\title{
Commentary: COVID-19 and mental health equity in the United States
}

\author{
Eileen M. Condon ${ }^{1}$, Amanda M. Dettmer' ${ }^{2}$ Dylan G. Gee ${ }^{3}$, Cheyanne Hagan ${ }^{2}$, \\ Ka Shu Lee ${ }^{2,4,5 *}$, Linda C. Mayes ${ }^{2}$, Carla S. Stover ${ }^{2}$ and Wan-Ling Tseng ${ }^{2}$ \\ ${ }^{1}$ Yale School of Nursing, New Haven, CT, United States, ${ }^{2}$ Yale Child Study Center, Yale School of Medicine, New Haven, CT, \\ United States, ${ }^{3}$ Department of Psychology, Yale University, New Haven, CT, United States, ${ }^{4}$ Division of Psychology and \\ Language Sciences, Faculty of Brain Sciences, University College London, London, United Kingdom, ${ }^{5}$ Anna Freud National \\ Centre for Children and Families, London, United Kingdom
}

Keywords: COVID-19, early stress, adversity, developmental psychopathology, long-term strategies

\section{A Commentary on}

COVID-19 and mental health equity in the United States

by Purtle, J. (2020). Soc. Psychiatry Psychiatr. Epidemiol. 1-3. doi: 10.1007/s00127-020-01896-8

\section{INTRODUCTION}

\section{OPEN ACCESS}

Edited by:

Sangeeta Chattoo,

University of York, United Kingdom

Reviewed by:

Frank Keating,

University of London, United Kingdom

${ }^{*}$ Correspondence:

Ka Shu Lee

kashu.lee@yale.edu

Specialty section:

This article was submitted to Medical Sociology,

a section of the journal

Frontiers in Sociology

Received: 17 July 2020 Accepted: 16 October 2020 Published: 19 November 2020

Citation:

Condon EM, Dettmer AM, Gee DG

Hagan C, Lee KS, Mayes LC,

Stover CS and Tseng W-L (2020) Commentary: COVID-19 and mental health equity in the United States.

Front. Sociol. 5:584390.

doi: $10.3389 /$ fsoc. 2020.584390
A recent commentary in Social Psychiatry and Psychiatric Epidemiology emphasized the disproportionately adverse mental health impacts of the COVID-19 pandemic (Purtle, 2020). While this perspective focused specifically on disparities in financial insecurity and grief stemming from disparities in COVID-19 mortality in adults, we expand this view to incorporate a developmental perspective of the pre-existing inequities experienced by children and families that have been magnified by COVID-19 in the United States.

The COVID-19 pandemic is an abrupt and chronic stressor that puts many children and adolescents at risk for developing mental and behavioral health disorders-particularly those from disadvantaged backgrounds and marginalized communities, as the pandemic has illustrated in the U.S. Before the COVID-19 pandemic, these children were already more likely to experience severe economic hardship, lack access to quality education and other resources critical for coping with adversities, and be at increased risk for maltreatment and exposure to home or community violence, all of which can result in increased risk for adverse health outcomes (Nurius et al., 2015; Jones et al., 2018). Moreover, BIPOC (Black, Indigenous, People of Color) families in the U.S. face systemic racism and discrimination. These inequities are only magnified and perpetuated by the COVID-19 pandemic (Figure 1) (Beaunoyer et al., 2020; Hooper et al., 2020; Turner Lee, 2020a; Van Dorn et al., 2020).

\section{TOXIC STRESS-MAGNIFIED}

A "toxic stress" response occurs when the resources that support children during adversities become taxed or depleted. Caregivers play a central role in buffering stress early in life (Gunnar and Donzella, 2002; Gee et al., 2014), and how caregivers respond to children's stress and convey information about traumatic events has critical effects on children's mental health following trauma (Carpenter et al., 2017). Sudden increases in stress due to the challenges of the COVID19 pandemic, such as increased viral exposure, even more restricted resources due to increased job, food, housing, and healthcare insecurity, and forced choices between work and childcare, may 


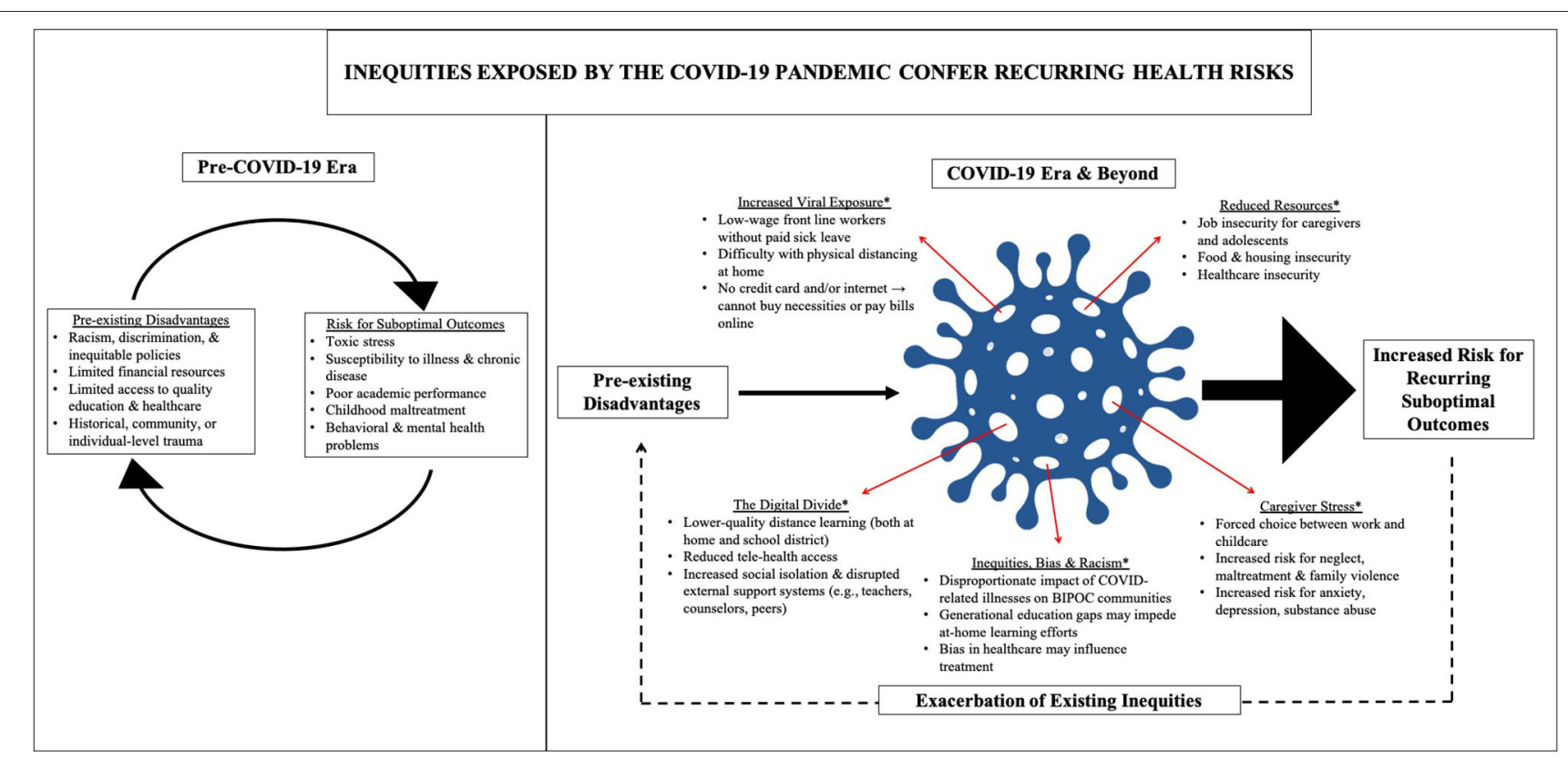

FIGURE 1 | The COVID-19 pandemic magnifies and exacerbates existing inequities (left) for disadvantaged children and families in the United States (indicated by thicker arrows in right), thereby placing them at greater risk for recurring suboptimal health outcomes and exacerbation of existing inequities. The asterisks $\left({ }^{*}\right)$ denote increased risk factors for disadvantaged children and families during COVID-19, which are not mutually exclusive. These are also potential points for intervention.

impair caregivers' ability to provide nurturing, sensitive parenting to help children cope with abrupt lifestyle changes (Cluver et al., 2020; Humphreys et al., 2020; Jain, 2020; Oppel et al., 2020; Power et al., 2020; Van Lancker and Parolin, 2020; Visual Capitalist, 2020).

With long-term major upheavals in daily life and widespread school closures in the U.S., the COVID-19 pandemic is likely to be particularly stressful and compromise the buffering effects of caregiving for families in marginalized or disadvantaged communities. School closures meant that children's support systems outside of the home were disrupted, with less support from teachers and peers, along with disruptions in mental health services provided by schools. For the 22 million children who rely on schools for meals, food insecurity has increased (Bauer, 2020), in part because there was no federal mandate that schools continue to offer food services during closures (Dunn et al., 2020; Van Lancker and Parolin, 2020). Job and housing insecurity have further impacted disadvantaged families (Grinstein-Weiss et al., 2020), and stress may be particularly acute for adolescents who work to support their families. Many caregivers from lower-income families are essential workers (e.g., grocery clerks, sanitation workers, public transportation drivers) whose jobs cannot be done remotely and/or do not offer paid sick leave. Such essential workers thus risk being infected at work or bringing the infection home (Visual Capitalist, 2020). School and daycare closures meant that many caregivers without the means and support for childcare were forced to prioritize job security over health. Existing educational disparities have been and will continue to be amplified for disadvantaged children, who are more likely to lack resources essential to distance learning and have fewer familial resources to support learning at home (Connecticut State Department of Education, 2020; Turner Lee, 2020a,b). Further, material hardship and deprivation may hinder brain development that supports functions such as literacy, problem-solving, decision-making, and emotion regulation, which are important for developing resilience and coping with future stressors (Johnson et al., 2016).

\section{DISCUSSION}

In these ways, the COVID-19 pandemic will have disproportionately long-lasting negative effects on the most vulnerable children and families in the U.S., including those living in poverty or with prior trauma histories, which are strong predictors of risk for mental health disorders (McLaughlin et al., 2012). Of particular concern is increased risk for maltreatment and exposure to family violence (Humphreys et al., 2020). Parenting stress, economic instability, and substance abuse are major risk factors for abuse and neglect (Stith et al., 2009) that are likely to be heightened during the pandemic. Unfortunately, detection of abuse and thus the potential to prevent it or intervene may be substantially impeded due to reduced contact with educators and healthcare providers, two primary sources of referrals to children's services. Though estimates of maltreatment exposure and referrals are not yet available, media and agency reports in the country have noted marked declines in referrals to child protection but increases in calls by minors to domestic violence and abuse hotlines.

Given the vast existing social and economic inequities across societies, it should come as no surprise that an abrupt stressor 
like COVID-19 has a disproportionate effect on disadvantaged and marginalized children. Pre-existing disadvantages that lead to increased viral exposure, including lack of quality health care, childcare, and paid sick leave, also have downstream consequences that put all individuals at risk (Woolf, 2017). This public health crisis should be taken as a call to action not only to meet the immediate needs of disadvantaged children, but also to support long-term strategies to dismantle the policies and institutional structures that systematically oppress low-income and BIPOC families across the country. Investment in interventions and adoption of policies that build on family strengths, including but not limited to early home visiting, school-based health centers, a living wage, paid family leave, and universal healthcare and childcare, are critical.

The health of a society depends on how well it invests in and cares for its most vulnerable. The COVID-19 pandemic highlights what we already know: we need to do better.

\section{REFERENCES}

Bauer, L. (2020). The COVID-19 Crisis Has Already Left Too Many Children Hungry in America. Available online at: https://www.brookings.edu/blog/upfront/2020/05/06/the-covid-19-crisis-has-already-left-too-many-childrenhungry-in-america/ (accessed July 15, 2020)

Beaunoyer, E., Dupéré, S., and Guitton, M. J. (2020). COVID-19 and digital inequalities: reciprocal impacts and mitigation strategies. Comput. Hum. Behav. 111:106424. doi: 10.1016/j.chb.2020.106424

Carpenter, A. L., Elkins, R. M., Kerns, C., Chou, T., Greif Green, J., and Comer, J. S. (2017). Event-related household discussions following the Boston Marathon bombing and associated posttraumatic stress among area youth. J. Clin. Child Adolesc. Psychol. 46, 331-342. doi: 10.1080/15374416.2015.1063432

Cluver, L., Lachman, J. M., Sherr, L., Wessels, I., Krug, E., Rakotomalala, S., et al. (2020). Parenting in a time of COVID-19. Lancet 395:e64. doi: 10.1016/S0140-6736(20)30736-4

Condon, E. M., Dettmer, A. M., Gee, D. G., Hagan, C., Lee, K. S., Mayes, L. C., et al. (2020). COVID-19 exposes enduring inequities for children and families. PsyArXiv [Preprint]. doi: 10.31234/osf.io/28vsj

Connecticut State Department of Education (2020). Student Participation in Distance Learning: Device/Connectivity Needs, Effective Strategies, Challenges, and State Supports Needed. Available online at: https://portal.ct.gov/-/media/ SDE/Performance/Research-Library/Results-from-District-Survey-onStudent-Participation-in-Distance-Learning-and-Device-Connectivity-N.pdf (accessed July 14, 2020).

Dunn, C. G., Kenney, E., Fleischhacker, S. E., and Bleich, S. N. (2020). Feeding low-income children during the Covid-19 pandemic. N. Engl. J. Med. 382:e40. doi: 10.1056/NEJMp2005638

Gee, D. G., Gabard-Durnam, L., Telzer, E. H., Humphreys, K. L., Goff, B., Shapiro, M., et al. (2014). Maternal buffering of human amygdala-prefrontal circuitry during childhood but not during adolescence. Psychol. Sci. 25, 2067-2078. doi: 10.1177/0956797614550878

Grinstein-Weiss, M., Gupta, B., Chun, Y., Lee, H., and Despard, M. (2020). Housing Hardships Reach Unprecedented Heights During the COVID-19 Pandemic. Available online at: https://www.brookings.edu/blog/up-front/ 2020/06/01/housing-hardships-reach-unprecedented-heights-during-thecovid-19-pandemic/ (accessed July 15, 2020)

Gunnar, M. R., and Donzella, B. (2002). Social regulation of the cortisol levels in early human development. Psychoneuroendocrinology 27, 199-220. doi: 10.1016/S0306-4530(01)00045-2

Hooper, M. W., Nápoles, A. M., Pérez-Stable, E. J. (2020). COVID-19 and racial/ethnic disparities. JAMA 323, 2466-2467. doi: 10.1001/jama.2020.8598

\section{AUTHOR CONTRIBUTIONS}

All authors contributed equally in writing the manuscript. EC and $\mathrm{AD}$ designed the figure.

\section{FUNDING}

AD was supported by a Clinical Science and Translational Award to Yale University from the National Center for Advancing Translational Sciences (UL1TR001863). EC holds a postdoctoral position funded by the National Institute of Nursing Research of the National Institutes of Health (K99NR018876).

\section{ACKNOWLEDGMENTS}

The early version of the manuscript has previously appeared online as a preprint at Condon et al. (2020). All authors are members of the Yale Early Stress and Adversity Consortium.

Humphreys, K. L., Myint, M. T., and Zeanah, C. H. (2020). Increased risk for family violence during the COVID-19 pandemic. Pediatrics 145:e20200982. doi: 10.1542/peds.2020-0982

Jain, R. (2020). Emerging Data on COVID-19 Related Morbidity and Mortality Has Highlighted the Underlying Structural Racism That Leads to Minority Communities Bearing a Higher Burden of Disease. Amidst This, However, There Has Been False Reassurance About One Population in Particular: \#Children. Available online at: https://twitter.com/rjain92/status/1280116492793716737. (accessed July 14, 2020).

Johnson, S. B., Riis, J. L., and Noble, K. G. (2016). State of the art review: poverty and the developing brain. Pediatrics 137:e20153075. doi: 10.1542/peds.2015-3075

Jones, T. M., Nurius, P., Song, C., and Fleming, C. M. (2018). Modeling life course pathways from adverse childhood experiences to adult mental health. Child Abuse Negl. 80, 32-40. doi: 10.1016/j.chiabu.2018.03.005

McLaughlin, K. A., Green, J. G., Gruber, M. J., Sampson, N. A., Zaslavsky, A. M., and Kessler, R. C. (2012). Childhood adversities and first onset of psychiatric disorders in a national sample of US adolescents. Arch. Gen. Psychiatry 69, 1151-1160. doi: 10.1001/archgenpsychiatry.2011.2277

Nurius, P. S., Green, S., Logan-Greene, P., and Borja, S. (2015). Life course pathways of adverse childhood experiences toward adult psychological well-being: a stress process analysis. Child Abuse Negl. 45, 143-153. doi: 10.1016/j.chiabu.2015.03.008

Oppel, R. A., Gebeloff, R., Lai, K. K. R., Wright, W., and Smith, M. (2020). The Fullest Look Yet at the Racial Inequity of Coronavirus. Available online at: https://www.nytimes.com/interactive/2020/07/05/us/coronaviruslatinos-african-americans-cdc-data.html (accessed July 15, 2020)

Power, M., Doherty, B., Pybus, K., and Pickett, K. (2020). How COVID-19 has exposed inequalities in the UK food system: the case of UK food and poverty. Emerald Open Res. 2:11. doi: 10.35241/emeraldopenres.13539.2

Purtle, J. (2020). COVID-19 and mental health equity in the United States. Soc. Psychiatry Psychiatr. Epidemiol. 55, 1-3. doi: 10.1007/s00127-020-01896-8

Stith, S. M., Liu, T., Davies, L. C., Boykin, E. L., Alder, M. C., Harris, J. M., et al. (2009). Risk factors in child maltreatment: a meta-analytic review of the literature. Aggress. Violent Behav. 14, 13-29. doi: 10.1016/j.avb.2006.03.006

Turner Lee, N. (2020a). What the Coronavirus Reveals About the Digital Divide Between Schools and Communities. Available online at: https://www.brookings. edu/blog/techtank/2020/03/17/what- the-coronavirus-reveals-about- thedigital-divide-between-schools-and-communities/ (accessed July 14, 2020).

Turner Lee, N. (2020b). Bridging Digital Divides Between Schools and Communities. Available online at: https://www.brookings.edu/research/bridging-digitaldivides-between-schools-and-communities/ (accessed July 14, 2020). 
Van Dorn, A., Cooney, R. E., and Sabin, M. L. (2020). COVID19 exacerbating inequalities in the US. Lancet 395:1243. doi: 10.1016/2FS0140-6736(20)30893-X

Van Lancker, W., and Parolin, Z. (2020). COVID-19, school closures, and child poverty: a social crisis in the making. Lancet Public Health 5, e243-e244. doi: 10.1016/S2468-2667(20)30084-0

Visual Capitalist (2020). COVID-19 Occupational Risk Score. Available online at: https://www.visualcapitalist.com/wp-content/uploads/2020/04/covid-19occupational-risk-scores.html (accessed July 14, 2020).

Woolf, S. H. (2017). Progress in achieving health equity requires attention to root causes. Health Aff. 36, 984-991. doi: 10.1377/hlthaff.2017.0197
Conflict of Interest: The authors declare that the research was conducted in the absence of any commercial or financial relationships that could be construed as a potential conflict of interest.

Copyright (c) 2020 Condon, Dettmer, Gee, Hagan, Lee, Mayes, Stover and Tseng. This is an open-access article distributed under the terms of the Creative Commons Attribution License (CC BY). The use, distribution or reproduction in other forums is permitted, provided the original author(s) and the copyright owner(s) are credited and that the original publication in this journal is cited, in accordance with accepted academic practice. No use, distribution or reproduction is permitted which does not comply with these terms. 